\title{
Clinicopathological features, survival and risk in breast cancer survivors with thyroid cancer: an analysis of the SEER database
}

Shuting Li', Jiao Yang ${ }^{1}$, Yanwei Shen ${ }^{1}$, Xiaoai Zhao ${ }^{1}$, Lingxiao Zhang ${ }^{1}$, Biyuan Wang ${ }^{1}$, Pan Li', Yunmei Wang², Min $\mathrm{Yi}^{3}$ and Jin Yang ${ }^{1 *}$

\begin{abstract}
Background: The co-occurrence of breast cancer (BC) and thyroid cancer (TC) has been mentioned for several years, researchers observed an increased risk of BC patients to develop TC, but few researches concern about the features, survival of BC patients followed by TC and the influent factors of the incidence risk. The present study aimed to estimate the clinicopathological features, survival of BC survivors who had primary TC and the predictive factors on the risk of BC patients to develop TC.

Methods: Women diagnosed with BC between 1992 and 2011, and then developed TC from the Surveillance, Epidemiology, and End Results Database were included. Standardized incidence ratios (SIRs) was used to perform multiple primary analyses, generated from the multiple primary-SIR program in SEER*Stat.

Results: A total of 842 BC then TC patients were included, the median age was 54 years. Additionally, $78.39 \%$ were white, $60.45 \%$ had $\mathrm{T} 1$ cancer, $62.47 \%$ had negative lymph nodes, and more than $75 \%$ had infiltrating duct carcinoma, 5-year survival rate was $95.4 \%$. Compared with BC only patients, they were younger, had smaller tumor size and a relatively better prognosis. The risk of developing TC was higher in BC patients than in the general population (SIR 1.22, $95 \% \mathrm{Cl}[1.14,1.31])$, especially within 3 years. The influent factors of SIR were black race, BC tumor site, grade and ER/PR positive expression.

Conclusions: BC patients followed by TC had its particular clinicopathological features. Compared with the features and survival of $\mathrm{BC}$ only patients, they were younger, had a smaller tumor size and a relatively better prognosis. Furthermore, BC patients had a high risk of developing TC, especially within 3 years. Black women, primary tumor located in an upper-outer, central, or overlapping site, high grade tumor and with positive hormone receptor expression were predictive factors to develop TC.
\end{abstract}

Keywords: Breast cancer, Thyroid cancer, Clinicopathological features, Survival, Standardized incidence ratios

\section{Introduction}

According to the 2012 GLOBOCAN statistics, breast cancer (BC) is the second most common cancer overall and the most frequently diagnosed cancer in women, with 1.67 million women diagnosed with $\mathrm{BC}$ worldwide [1]. Because of the high rate of survival and the relatively young age at diagnosis, the number of $\mathrm{BC}$ survivors is increasing, and therefore, there is a chance of experiencing other cancers. Five

\footnotetext{
* Correspondence: 1473106133@qq.com

${ }^{1}$ Department of Medical Oncology, the First Affiliated Hospital of Xi'an Jiaotong University, 277 West Yanta Road, Xi'an 710061, Shaanxi, China Full list of author information is available at the end of the article
}

most common cancers occurred in $\mathrm{BC}$ survivors are contralateral breast cancer (cumulative incidence at 8 years is $1.64 \%)$, urinary system cancer $(0.43 \%)$, lung cancer $(0.31 \%)$, thyroid cancer $(0.28 \%)$ and melanoma (0.21\%) [2]. Several articles have suggested that $\mathrm{BC}$ and thyroid cancer (TC) can occur together in female patients, and the rate of occurrence is much higher than that expected by chance [3]. Studies have evaluated the risk of developing second primary malignancies in patients with BC or TC history [2, 4-6], an increased risk of developing TC in $\mathrm{BC}$ survivors was observed. It is suspected that $\mathrm{BC}$ and $\mathrm{TC}$ share some common etiological factors [7-9], and some treatment-related factors may

(c) The Author(s). 2019 Open Access This article is distributed under the terms of the Creative Commons Attribution 4.0 International License (http://creativecommons.org/licenses/by/4.0/), which permits unrestricted use, distribution, and 
play a role in its co-occurrence. Besides, study on the comparison of features and prognosis between $\mathrm{BC}$ patients with TC and TC only patients was conducted [10]. However, few studies focused on the differences on clinicopathological features and prognosis between $\mathrm{BC}$ survivors with $\mathrm{TC}$ and $\mathrm{BC}$ only patients, the factors that influence the risk of $\mathrm{BC}$ survivors to develop TC is unclear.

The present study aimed to estimate the clinicopathological features, survival, risk and influent factors of SIRs on $\mathrm{BC}$ survivors followed by primary $\mathrm{TC}$ by analyzing the Surveillance, Epidemiology, and End Results (SEER) Database.

\section{Materials and methods Data source}

Data were obtained from 13 US registration centers in the SEER Database, a database programed by US National Cancer Institute, which collects, processes, and provides data on approximately $10 \%$ of the US population, using the SEER"Stat software program (version 8.3.2; http://seer.cancer.gov/seerstat; accessed April 14, 2016) under a user agreement. In order to obtain data of $\mathrm{BC}$ patients who subsequently developed TC and had the follow-up records for at least 2 years until 2013, we used the database to identify patients whose primary tumor site codes were C50.0-C50.9, and histology codes were 8500/3 (infiltrating duct carcinoma), 8520/3 (lobular carcinoma), 8521/3 (infiltrating ductular carcinoma), 8522/3 (infiltrating duct and lobular carcinoma), 8523/3 (infiltrating duct mix with other types of carcinoma), 8524/3 (infiltrating lobular mix with other types of carcinoma), and 8541/3 (Paget disease and infiltrating ductal carcinoma of breast) from 1992 to 2011. Considering the opinion accepted by most scholars that occurrence of 2 types of cancers within 6 months is mainly considered as simultaneous occurrence, the latency between $\mathrm{BC}$ and $\mathrm{TC}$ was required at least 6 months. $\mathrm{BC}$ only cohort also met the site codes, histology codes and follow-up years criteria mentioned above, but the number of primary malignancies was only one.

A total of 842 cases matched the criteria and composed of $\mathrm{BC}$ then developing TC cohort, 332,424 patients composed of $\mathrm{BC}$ only cohort. All patients were followed until last known follow-up, death, or December 31, 2013, whichever occurred first. Data, including basic patient information, clinical features, pathologic characteristics, standard incidence rates, and survival information, were collected.

\section{Statistical methods}

Overall survival (OS) was defined as the time from the diagnosis of $\mathrm{BC}$ to the time of death from any cause or loss of contact. OS curves were calculated using the Kaplan-Meier method. Cox proportional hazards models were used to evaluate the influence of collected clinicopathological factors on OS of BC then TC patients. Different factors have different impact on patients' survival, after adjusting for the influence of other factors, a certain factor may have individual impact on survival, reflecting on the $p$ value $<0.05$ in Cox proportional hazards models, this factor was known as a prognostic factor. The standardized incidence ratios (SIRs) was used to perform multiple primary analyses, generated from the multiple primary-SIR program in SEER"Stat (version 8.3.2; April 14, 2016). SIR was used to compare the incidence rate for the cohort of patients previously diagnosed with $\mathrm{BC}$ and subsequently diagnosed with $\mathrm{TC}$ to that expected in the general population. SIR $=$ standardized incidence rate of $\mathrm{BC}$ patients to develop TC / standardized incidence rate of general population to develop TC. SIR $>1$ means $\mathrm{BC}$ patients have more risk to develop TC than general women, factors with a $\operatorname{SIR}>1$ and $p$ value $<0.05$ was known as a predictive factor. Statistical analyses were performed using SPSS version 21.0 (IBM Corp., Armonk, NY, USA). All statistical tests were two-tailed, and $p<0.05$ was considered significant.

\section{Results \\ Differences between the clinicopathological features of $B C$ then $\mathrm{TC}$ group and $\mathrm{BC}$ only group}

Clinicopathological features of $\mathrm{BC}$ then $\mathrm{TC}$ group and $\mathrm{BC}$ only group are presented in Table 1 . With regard to the features of $\mathrm{BC}$ patients followed by $\mathrm{TC}$, more than half of the patients were more than 50 years when diagnosed with $\mathrm{BC}$, and the largest age group was 51-60 years, only $11.28 \%$ of the $\mathrm{BC}$ survivors with primary TC were diagnosed before 40 years of age. Regarding race, white women represented $78.39 \%$ of the patients, which mainly due to the composition of the population. Regarding other pathological features, more than $1 / 3$ of the patients had BC in the upper-outer quarter, $60.45 \%$ had T1 cancer, $62.47 \%$ had negative lymph nodes, more than $3 / 4$ had infiltrating duct carcinoma, more than $1 / 3$ had grade 2 or 3 histology, and more than half were hormone receptor-positive cancer. Compared these features with those of $\mathrm{BC}$ only patients, some particular features were obtained. BC patients followed by TC showed a significantly younger median age at diagnosis ( 54 vs 59 , $p<0.001)$ and accordingly had more patients of $<50$ years group (37.41\% vs $28.58 \%$ ). Considering tumor features, BC sizes between two groups were significantly different, $\mathrm{BC}$ patients followed by $\mathrm{TC}$ had more small size $(\mathrm{T} \leq 20 \mathrm{~mm})$ tumors.

\section{Survival and survival influent factors of $B C$ patients followed by TC}

Kaplan-Meier curves were used to demonstrate the OS curves. The 5-year OS rate of $\mathrm{BC}$ then TC patients was $95.4 \%$, BC only patients was $88.9 \%$. 
Table 1 Clinicopathological features of 842 breast cancer patients followed by thyroid cancer and 332,424 breast cancer only patients

\begin{tabular}{|c|c|c|c|c|c|}
\hline & \multicolumn{2}{|c|}{ Breast cancer then develop thyroid cacer, $n=842$} & \multicolumn{2}{|c|}{ Breast cancer only, $n=332,424$} & \multirow{2}{*}{$\begin{array}{l}p- \\
\text { value }\end{array}$} \\
\hline & $\bar{n}$ & $\%$ & n & $\%$ & \\
\hline Age at diagnosis & & & & & $<0.001$ \\
\hline Median age (years) & $54[47,63]$ & & $59[49,71]$ & & \\
\hline$\leq 40$ & 95 & $11.28 \%$ & 25,787 & $7.76 \%$ & \\
\hline $41-50$ & 220 & $26.13 \%$ & 69,214 & $20.82 \%$ & \\
\hline $51-60$ & 257 & $30.52 \%$ & 80,754 & $24.29 \%$ & \\
\hline $61-70$ & 172 & $20.43 \%$ & 70,475 & $21.20 \%$ & \\
\hline$>70$ & 98 & $11.64 \%$ & 86,194 & $25.93 \%$ & \\
\hline Race & & & & & 0.106 \\
\hline White & 660 & $78.39 \%$ & 267,366 & $80.43 \%$ & \\
\hline Black & 77 & $9.14 \%$ & 30,469 & $9.17 \%$ & \\
\hline American Indian & 6 & $0.71 \%$ & 2267 & $0.68 \%$ & \\
\hline Asian or Pacific Islander & 97 & $11.52 \%$ & 30,311 & $9.12 \%$ & \\
\hline Unknown & 2 & $0.24 \%$ & 2011 & $0.60 \%$ & \\
\hline Tumor site & & & & & 0.912 \\
\hline Central portion & 55 & $6.53 \%$ & 18,578 & $5.59 \%$ & \\
\hline Nipple & 3 & $0.37 \%$ & 1889 & $0.66 \%$ & \\
\hline Upper-inner & 90 & $10.69 \%$ & 34,580 & $10.40 \%$ & \\
\hline Lower-inner & 44 & $5.22 \%$ & 17,684 & $5.32 \%$ & \\
\hline Upper-outer & 301 & $35.75 \%$ & 116,708 & $35.11 \%$ & \\
\hline Lower-outer & 56 & $6.65 \%$ & 22,500 & $6.77 \%$ & \\
\hline Overlapping lesion & 167 & $19.83 \%$ & 68,460 & $20.59 \%$ & \\
\hline Unknown & 126 & $14.96 \%$ & 52,033 & $15.65 \%$ & \\
\hline Tumor size & & & & & $<0.001$ \\
\hline $\mathrm{T} \leq 20 \mathrm{~mm}$ & 509 & $60.45 \%$ & 186,656 & $56.15 \%$ & \\
\hline $21 \mathrm{~mm}<\mathrm{T} \leq 50 \mathrm{~mm}$ & 235 & $27.91 \%$ & 88,752 & $26.70 \%$ & \\
\hline $\mathrm{T}>50 \mathrm{~mm}$ & 39 & $4.63 \%$ & 14,467 & $4.35 \%$ & \\
\hline Unknown & 59 & $7.01 \%$ & 42,553 & $12.80 \%$ & \\
\hline Positive lymph nodes & & & & & 0.358 \\
\hline 0 & 526 & $62.47 \%$ & 198,449 & $59.70 \%$ & \\
\hline $1-3$ & 174 & $20.66 \%$ & 71,560 & $21.53 \%$ & \\
\hline $4-9$ & 55 & $6.53 \%$ & 22,700 & $6.83 \%$ & \\
\hline$\geq 10$ & 27 & $3.21 \%$ & 14,593 & $4.38 \%$ & \\
\hline Unknown & 60 & $7.13 \%$ & 25,127 & $7.56 \%$ & \\
\hline Histology & & & & & 0.650 \\
\hline Infiltrating duct carcinoma & 689 & $81.83 \%$ & 267,864 & $80.57 \%$ & \\
\hline Lobular carcinoma & 71 & $8.43 \%$ & 29,570 & $8.90 \%$ & \\
\hline Mixed & 82 & $9.74 \%$ & 34,993 & $10.53 \%$ & \\
\hline Grade & & & & & 0.351 \\
\hline 1 & 136 & $16.15 \%$ & 56,672 & $17.05 \%$ & \\
\hline 2 & 350 & $41.57 \%$ & 130,229 & $39.18 \%$ & \\
\hline 3 & 283 & $33.61 \%$ & 111,645 & $33.58 \%$ & \\
\hline 4 & 13 & $1.54 \%$ & 4636 & $1.39 \%$ & \\
\hline
\end{tabular}


Table 1 Clinicopathological features of 842 breast cancer patients followed by thyroid cancer and 332,424 breast cancer only patients (Continued)

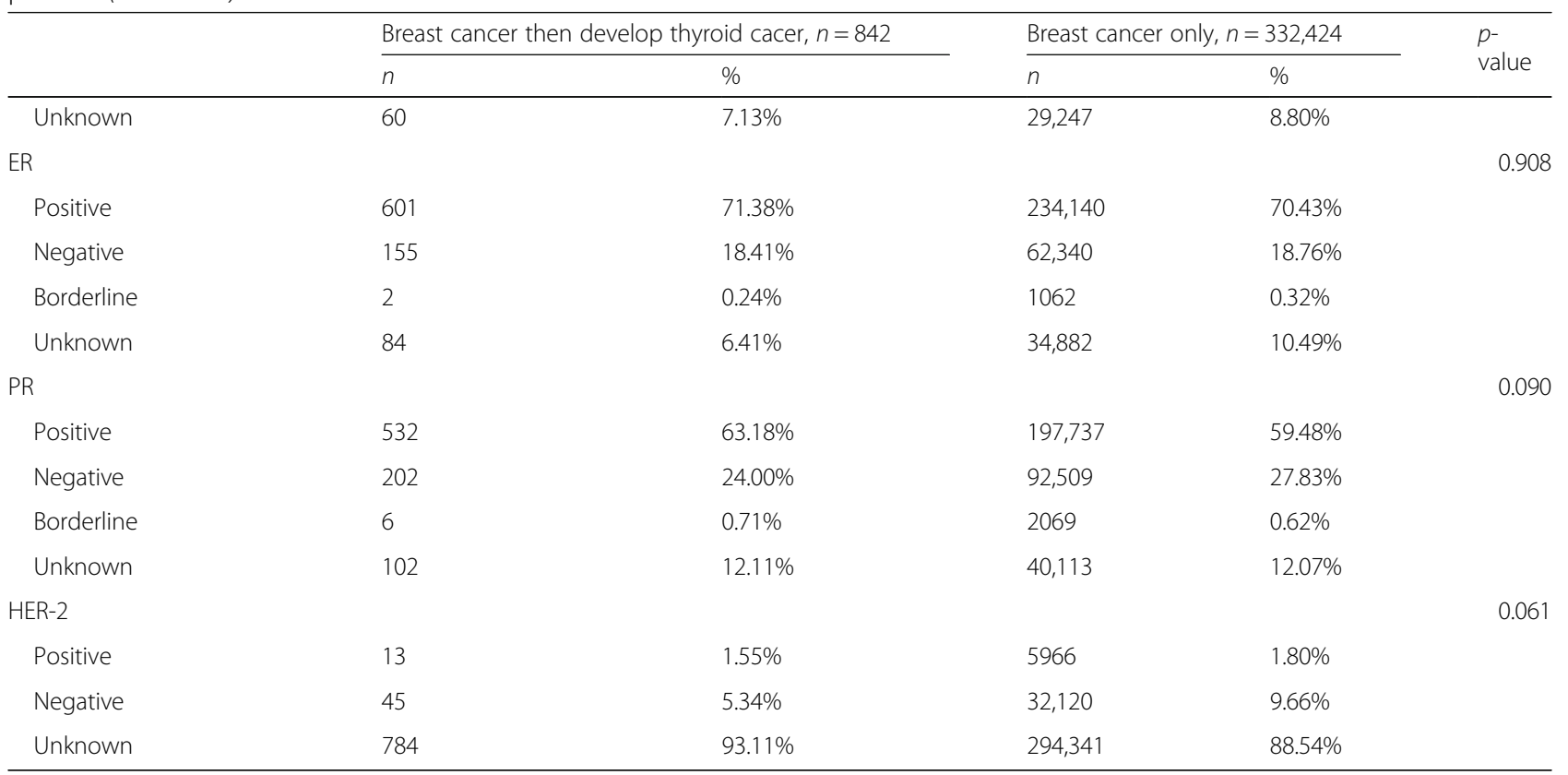

ER Estrogen receptor, PR Progesterone receptor, HER-2 Human epidermal growth factor receptor 2

Cox proportional hazards models were used to evaluate the influence of collected clinicopathological factors on OS of patients developed TC after BC diagnosis, results are summarized in Table 2. After adjusting for the influence of other factors, $p$ value $<0.05$ in Cox proportional hazards models indicates this factor as a prognostic factor, which means BC then TC patients with this feature have an increased probability to get a worse prognosis. In Table 2, After adjusting for the influence of other factors, the age at diagnosis of $\mathrm{BC}(p<0.001)$ and the number of positive lymph nodes $(p<0.001)$ were prognostic factors of $\mathrm{BC}$ patients followed by TC. With regard to age, using $\leq 40$ years as a reference, $61-70$ and $>70$ age groups had a relatively worse prognosis. With regard to lymph nodes, when zero positive metastatic lymph nodes was used as a reference, with the increase in the number of positive metastatic lymph nodes, the shorter OS was obtained.

In order to determine the lowest cut-off age that could indicate a significantly different prognosis, the contiguous age with different survival was analyzed in SPSS, and 43 years of age was identified as the lowest cut-off age with significantly different prognosis on both sides $(p=$ 0.022). Considering the utility in clinic, 50 years was selected as the cut-off age finally, survival curves were summarized in Fig. 1. Two separate OS curves were represented in Fig. 1 when grouped by age 50, patients younger than 50 exhibited a significant advantage for OS. Figure 2 demonstrates the survival curves of different positive lymph node number groups, and 5 separate curves were noted in the figure $(p<0.001)$. With the

Table 2 Cox proportional hazards analysis on overall survival of 842 breast cancer patients followed by thyroid cancer

\begin{tabular}{lll}
\hline Variable & HR $(\mathrm{Cl})$ & $p$-value \\
\hline $\begin{array}{l}\text { Age at diagnosis } \\
\leq 40\end{array}$ & Reference & $<0.001$ \\
$41-50$ & $1.158(0.519-2.582)$ & 0.720 \\
$51-60$ & $1.613(0.737-3.533)$ & 0.232 \\
$61-70$ & $4.940(2.306-10.585)$ & $<0.001$ \\
$>70$ & $11.681(5.409-25.225)$ & $<0.001$ \\
Race & & 0.279 \\
Tumor site & & 0.520 \\
Tumor size & & 0.096 \\
Positive lymph nodes & & $<0.001$ \\
0 & Reference & \\
$1-3$ & $1.649(1.049-2.591)$ & 0.030 \\
$4-9$ & $2.440(1.235-4.821)$ & 0.010 \\
$\geq 10$ & $6.515(3.106-13.663)$ & $<0.001$ \\
Unknown & $2.054(1.200-3.417)$ & 0.009 \\
Histology & & 0.125 \\
Grade & & 0.321 \\
ER & & 0.831 \\
PR & & 0.767 \\
\hline
\end{tabular}

$H R$ Hazard ratio, $\mathrm{Cl}$ Confidence interval, $E R$ Estrogen receptor, $P R$ Progesterone receptor 


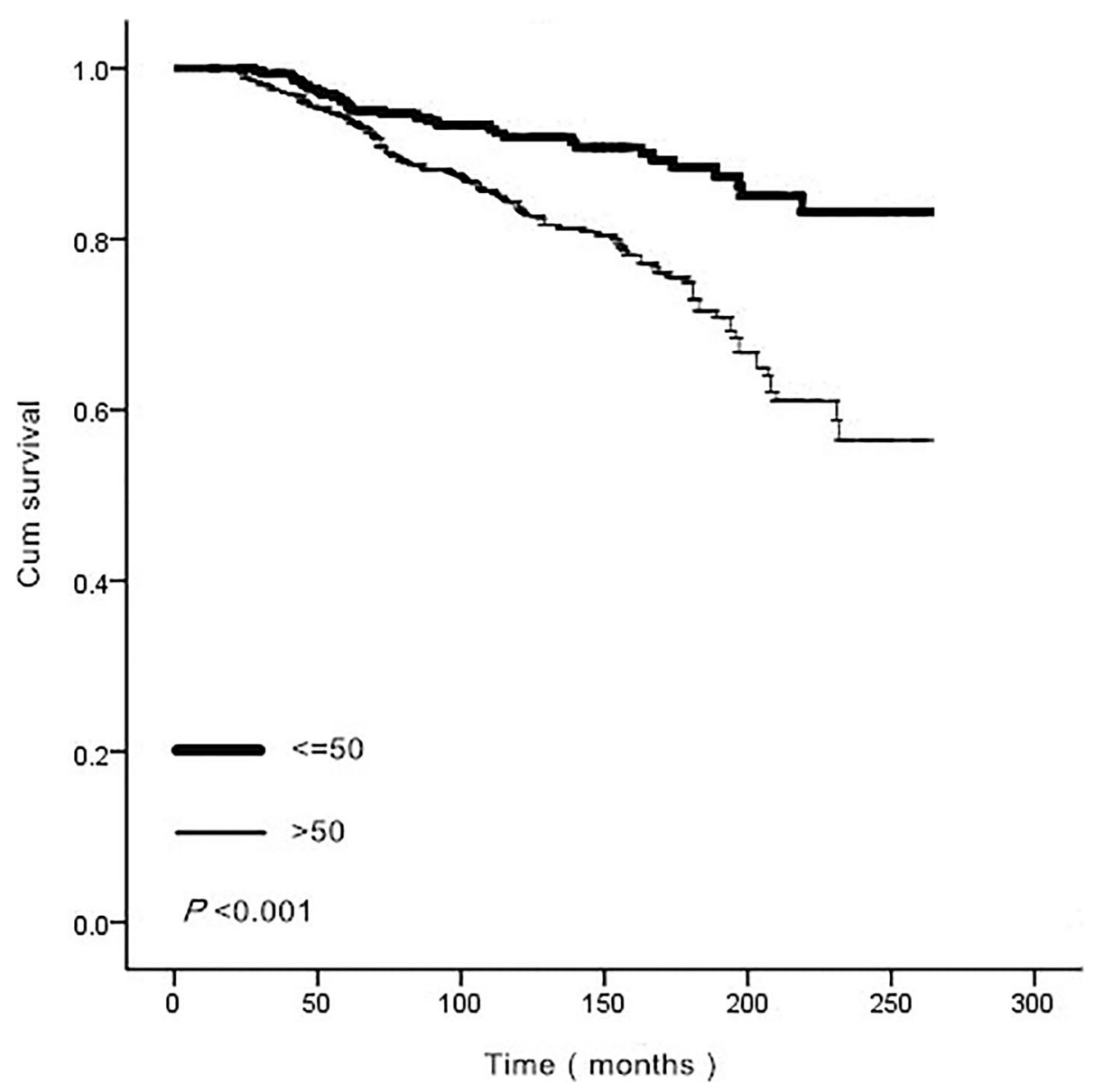

Fig. 1 Survival curves for an age 50 cut-off of 842 breast cancer patients followed by thyroid cancer

increase of positive lymph nodes number, a worse prognosis was obtained.

SIR and SIR influent factors of BC patients followed by TC In our study, the SIR was used to compare the incidence rate for the cohort of patients previously diagnosed with $\mathrm{BC}$ and subsequently diagnosed with $\mathrm{TC}$ to that expected in the general population. SIR $>1$ means $\mathrm{BC}$ patients have more risk to develop $\mathrm{TC}$ than general women. We compared the standardized incidence rate of $\mathrm{BC}$ patients with a certain feature with that of general women with the same feature, when the ratio (SIR) $>1$ and $p$ value $<0.05$, this feature was defined as a predictive factor, which indicates that $\mathrm{BC}$ patients with this feature had an increased probability to further develop TC. The SIR values were generated from the multiple primarySIR program in SEER $*$ Stat and results are summarized in Fig. 3 and Table 3. The SIR for develop TC was 1.22 $(95 \%$ CI $[1.14,1.31])$ in total.

The mean latency from diagnosis with $\mathrm{BC}$ to the development of TC was 65.7 months. The incidence of developing primary $\mathrm{TC}$ was significantly high within the first 3 years of $\mathrm{BC}$ diagnosis and then decreased, with no significantly difference from that of the general population (Fig. 3). Therefore, a latency of 3 years was used as the cut-off when evaluating the influence of other factors in Table 3.

Different influent factors were summarized in Table 3, when SIR $>1$ and $p$ value $<0.05$, this factor was defined as a predictive factor, which indicates that $\mathrm{BC}$ patients with this feature had an increased probability to further develop TC. When considering race, white, black, Asian, and Pacific Islander patients all had significant high SIRs. Black women with $\mathrm{BC}$ had the highest SIR of 1.88, and even beyond the 3-year latency, the risk was still higher in these patients to develop TC than in general black women (SIR 1.56, 95\% CI [1.14, 2.09]). The excess risk of black women was 1.61 per 10,000 persons, which was the highest in all SIR influent factors. With regard to the site of BC, tumors located in upper-outer quarter or central portion or overlapping lesions showed a significant increase in the risk of TC development (SIRs were $1.48,1.19$, and 1.19 , respectively). BC patients with high grade (grade 2 or 3 ) tumor also had significantly higher 


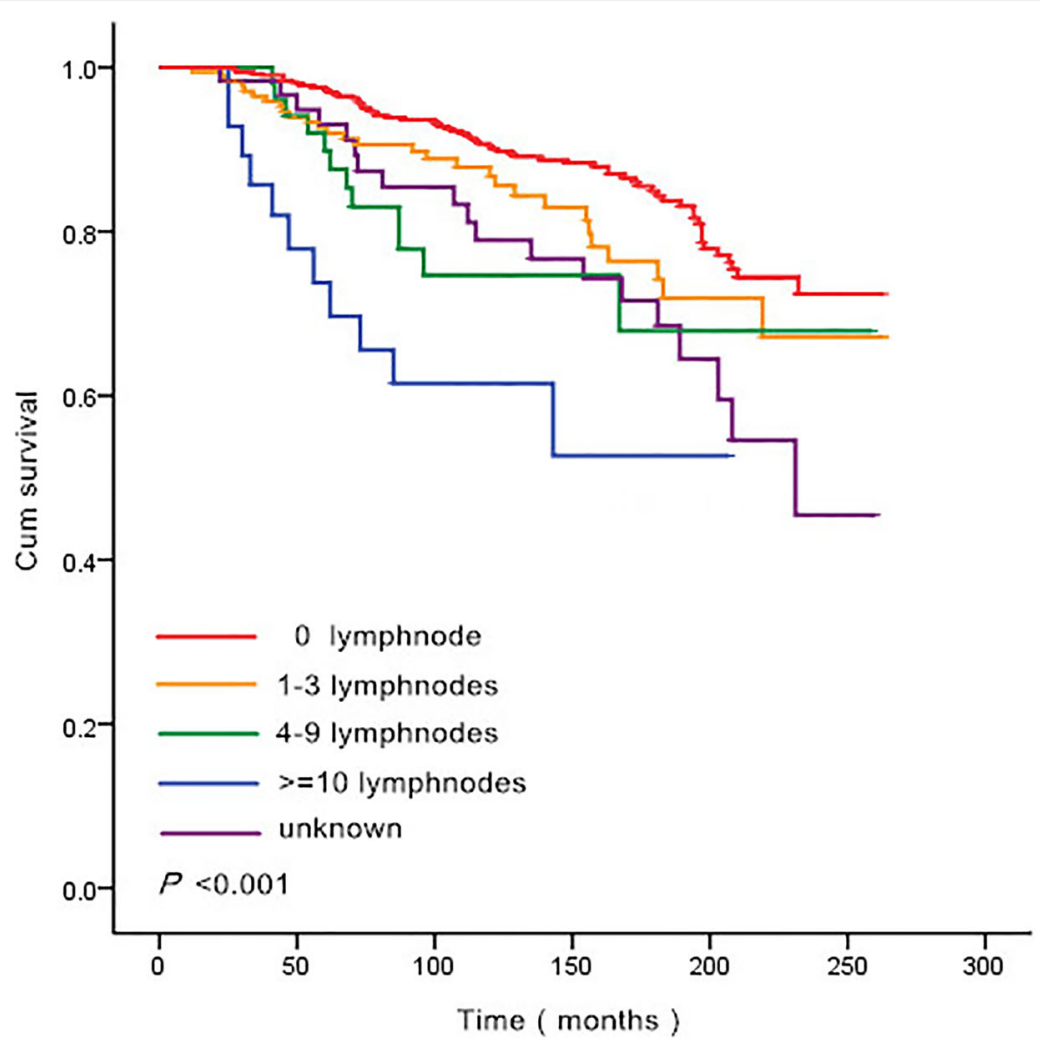

Fig. 2 Survival curves for different positive lymph node numbers of 842 breast cancer patients followed by thyroid cancer

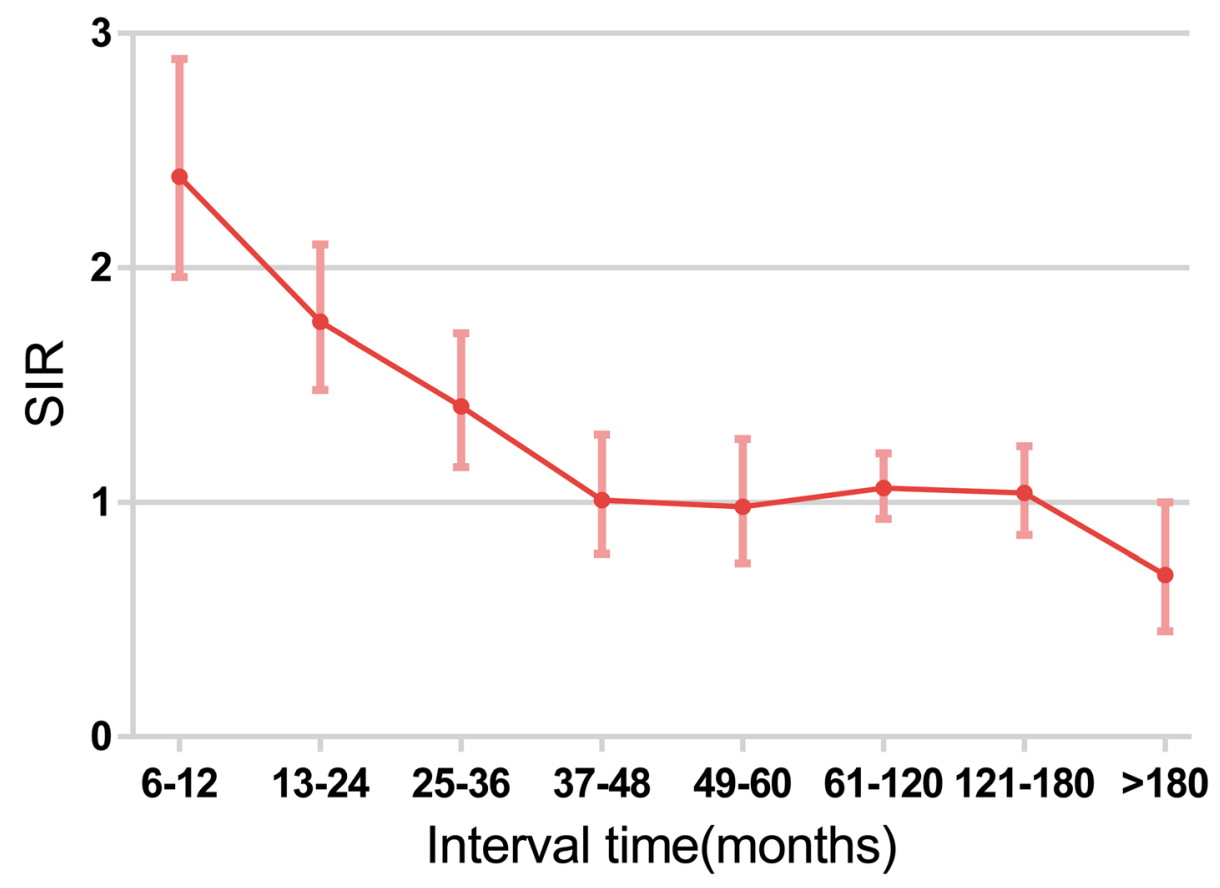

Fig. 3 Incidence rate ratios of 842 breast cancer patients followed by thyroid cancer, stratified by time interval 
Table 3 Incidence rate ratios of 842 breast cancer patients followed by thyroid cancer, stratified by factors

\begin{tabular}{|c|c|c|c|c|c|c|c|c|c|c|c|c|c|}
\hline \multirow[t]{2}{*}{ Variable } & \multicolumn{5}{|l|}{ Total } & \multicolumn{4}{|c|}{ 6-36 months } & \multicolumn{4}{|c|}{$>36$ months } \\
\hline & Observed & SIR & $\mathrm{Cl}$ low & $\mathrm{Cl}$ high & Excess risk & Observed & $\mathrm{SIR}$ & $\mathrm{Cl}$ low & $\mathrm{Cl}$ high & Observed & $\mathrm{SIR}$ & $\mathrm{Cl}$ low & $\mathrm{Cl}$ high \\
\hline \multicolumn{14}{|l|}{ Race } \\
\hline White & 660 & $1.15^{*}$ & 1.06 & 1.24 & 0.37 & 263 & $1.67^{* *}$ & 1.47 & 1.88 & 397 & 0.95 & 0.86 & 1.05 \\
\hline Black & 77 & $1.88^{* *}$ & 1.48 & 2.34 & 1.61 & 32 & $2.63^{* *}$ & 1.80 & 3.71 & 45 & $1.56^{*}$ & 1.14 & 2.09 \\
\hline Asian or Pacific Islander & 97 & $1.46^{*}$ & 1.18 & 1.78 & 1.19 & 43 & $2.19^{*}$ & 1.59 & 2.95 & 54 & 1.15 & 0.87 & 1.51 \\
\hline \multicolumn{14}{|l|}{ Site } \\
\hline Central portion & 55 & $1.48^{*}$ & 1.12 & 1.93 & 1.13 & 28 & $2.76^{* *}$ & 1.84 & 3.99 & 27 & 1.00 & 0.66 & 1.45 \\
\hline Upper-inner & 90 & 1.23 & 0.99 & 1.51 & 0.56 & 32 & $1.53^{*}$ & 1.05 & 2.16 & 58 & 1.11 & 0.84 & 1.43 \\
\hline Lower-inner & 44 & 1.20 & 0.87 & 1.62 & 0.49 & 17 & 1.64 & 0.96 & 2.63 & 27 & 1.03 & 0.68 & 1.50 \\
\hline Upper-outer & 301 & $1.19^{*}$ & 1.06 & 1.33 & 0.46 & 112 & $1.65^{*}$ & 1.36 & 1.98 & 189 & 1.02 & 0.88 & 1.18 \\
\hline Lower-outer & 56 & 1.20 & 0.91 & 1.56 & 0.50 & 20 & 1.50 & 0.92 & 2.32 & 36 & 1.08 & 0.76 & 1.50 \\
\hline Overlapping lesion & 167 & $1.19^{*}$ & 1.02 & 1.39 & 0.48 & 82 & $2.04^{* *}$ & 1.63 & 2.54 & 85 & 0.85 & 0.68 & 1.05 \\
\hline \multicolumn{14}{|l|}{ Grade } \\
\hline 1 & 136 & 1.12 & 0.94 & 1.33 & 0.31 & 45 & 1.26 & 0.92 & 1.68 & 91 & 1.07 & 0.86 & 1.31 \\
\hline 2 & 350 & $1.27^{*}$ & 1.14 & 1.41 & 0.66 & 134 & $1.72^{*}$ & 1.44 & 2.04 & 216 & 1.09 & 0.95 & 1.25 \\
\hline 3 & 283 & $1.30^{*}$ & 1.16 & 1.47 & 0.76 & 135 & $2.16^{* *}$ & 1.81 & 2.56 & 148 & 0.96 & 0.81 & 1.12 \\
\hline \multicolumn{14}{|l|}{ ER } \\
\hline Positive & 601 & $1.24^{*}$ & 1.14 & 1.34 & 0.59 & 242 & $1.71^{*}$ & 1.50 & 1.94 & 359 & 1.04 & 0.94 & 1.16 \\
\hline Negative & 155 & $1.25^{*}$ & 1.06 & 1.47 & 0.63 & 72 & $2.10^{* *}$ & 1.65 & 2.65 & 83 & 0.93 & 0.74 & 1.15 \\
\hline \multicolumn{14}{|l|}{$P R$} \\
\hline Positive & 532 & $1.27^{*}$ & 1.17 & 1.39 & 0.68 & 216 & $1.79^{* *}$ & 1.56 & 2.04 & 316 & 1.06 & 0.95 & 1.19 \\
\hline Negative & 202 & 1.15 & 0.99 & 1.32 & 0.36 & 92 & $1.78^{* *}$ & 1.44 & 2.19 & 110 & 0.88 & 0.71 & 1.06 \\
\hline ER (+) PR (+) & 507 & $1.26^{*}$ & 1.15 & 1.37 & 0.64 & 206 & $1.75^{* *}$ & 1.52 & 2.01 & 301 & 1.05 & 0.94 & 1.18 \\
\hline ER (-) PR (-) & 125 & 1.16 & 0.96 & 1.38 & 0.40 & 61 & $1.97^{*}$ & 1.51 & 2.53 & 64 & 0.83 & 0.64 & 1.06 \\
\hline
\end{tabular}

$S I R$ Standardized incidence ratio, $C I$ Confidence interval, ER Estrogen receptor, $P R$ Progesterone receptor ${ }^{*} p<0.05 ;{ }^{* *} p<0.01$

risk to develop TC. With regard to the status of hormone receptors, $\mathrm{BC}$ survivors were at a significantly high risk for developing $\mathrm{TC}$ when both the estrogen receptor (ER) and progesterone receptor (PR) were positive (SIR $1.26,95 \%$ CI $[1.15,1.37])$. But when only considered the SIR within 3 years of $\mathrm{BC}$ diagnosis, all $\mathrm{BC}$ survivors had a significantly high incidence to develop TC irrespective of ER or PR status.

\section{Discussion}

The possibility of a relation between $\mathrm{BC}$ and thyroid diseases has been considered for several years, and the foundation of this opinion is the breasts and thyroid are hormone responsive organs, which are closely related to endocrine function changes and glandular diseases [11]. One of the first studies to suggest this relationship was the study by Beatson [12] in 1896, in which thyroid extract was used in the treatment of $\mathrm{BC}$. Then, studies have evaluated the risk of developing second primary malignancies in patients with $\mathrm{BC}$ or TC history $[2,4-6]$, mainly concentrate on the influence of radiotherapy.
Some studies demonstrated that $\mathrm{BC}$ patients have more chance to develop second primary TC and vise versa [3, $7,9]$. Few studies have focused on the features and survival of $\mathrm{BC}$ survivors with $\mathrm{TC}$ and the factors that influence the risk of BC survivors to develop TC. Our study is novel in that it focused on the clinicopathological features, survival, and predictive factors of $\mathrm{BC}$ survivors who developed primary TC, based on the cohorts from the SEER database.

Table 1 shows that patients with both $\mathrm{BC}$ and $\mathrm{TC}$ were more likely to be white, have a median age of 54 years, have a tumor size less than $2 \mathrm{~cm}$, have no lymph nodes metastasis, show infiltrating duct pathology, show grade 2 or 3 histology, and with hormone receptors positivity. In a previous study, An et al. [3] investigated 81 $\mathrm{BC}$ patients followed by TC, median age at diagnosis of $\mathrm{BC}$ was $43.4,86.5 \% \mathrm{BC}$ were infiltrating duct carcinoma and ER, PR expressions increased significantly in $\mathrm{BC}$ patients. The present results are consistent with these above. Additionally, compared the clinicopathological features and prognosis with those of $\mathrm{BC}$ only patients, 
$\mathrm{BC}$ patients followed by $\mathrm{TC}$ were younger, had a significantly smaller tumor size, and had a relatively better prognosis. An earlier age at diagnosis, a smaller tumor and a well prognosis increased the chance of developing a second tumor in the following years, which few studies have mentioned before. With regard to the better prognosis of $\mathrm{BC}$ survivors with $\mathrm{TC}$, it mainly due to the early age at diagnosis, the 10-year survival of TC patients reaching 95-97\% [9] was another reason. Considering the factors that influence the survival of patients with both $\mathrm{BC}$ and $\mathrm{TC}$, age at diagnosis of $\mathrm{BC}$ and the number of positive lymph nodes were identified after adjustment, and these are known to be prognostic factors in BC only patients [13], seeming there is no much difference existed. As a clinician, by using these prognosis factors, we are able to identify patients who may get a worse survival, which give us a chance to make effort to improve their prognosis at the time of diagnosis or during patients' therapy.

The SIR for develop TC was 1.22 (95\% CI [1.14, 1.31]) in total, results from other studies range from 1.28 to $2.18[3,7,14,15]$. The significantly high SIR indicated $\mathrm{BC}$ patients had an increased risk for developing TC, which was not just the result of increased medical surveillance for breast cancer. Hormonal, genetic, and environmental factors, and treatment modalities might play roles in this co-occurrence $[3,9,14,16]$. Moreover, a common molecular mechanism might exist, rather than an incidental association. Researchers proposed ER/ PR signaling might represent common etiological factors in the development of $\mathrm{TC}$ and $\mathrm{BC}$, studies on the mechanism, including the ER pathway in thyroid tissues and mutations in the CHEK2 gene, have been reported previously $[3,14,17]$. Clinicopathological features in BC then TC group also showed a tendency in more positive expression of ER/PR than BC only group in Table 1. Several articles evaluating radiotherapy after $\mathrm{BC}$ diagnosis as a possible cause of the increased risk of second primary TC. Grantzau [4] conducted a meta-analysis of $762,468 \mathrm{BC}$ patients and found radiotherapy for breast cancer is associated with a small but significantly increased risk of second cancers of the lung, esophagus, and soft tissues, but no significant association between radiotherapy and second thyroid cancer. Another research [14] containing 55,318 women from the National Health Insurance system of Taiwan, compared the risk of $\mathrm{TC}$ among $\mathrm{BC}$ patients who received radiotherapy or not, the risk to develop $\mathrm{TC}$ in women who received radiotherapy was not significantly higher than those not. Some other research based on different nations agreed with the opinion that radioactive iodine therapy did not significantly increase the incidence of subsequent $\mathrm{BC}$ [18-20]. But a research by Wei Lin [21] showed the risk of TC did increase in some BC subgroups, adjusted hazard ratios of TC risk for women receiving radiotherapy was 1.97 among $\mathrm{BC}$ survivors aged older than 55 years, 1.93 among BC survivors without chemotherapy. Though radiotherapy may increase the risk of developing second TC in some subgroups of $\mathrm{BC}$ survivors, its role in $\mathrm{BC}$ treatment and the beneficial on OS overweight the risk for developing second TC.

The mean latency from diagnosis with $\mathrm{BC}$ to the development of TC was 65.7 months, this interval time was 5.6 years in the research of Garner et al. [9] and 5.9 years (range 3.4-12.7 years) in the research of An et al. [3]. A time interval of 3 years is essential for BC patients, for the risk of TC development was significantly higher within 3 years, with SIR of 2.39 (95\% CI [1.96, 2.89]) in the first year. An et al. [3] observed the incidence of second primary $\mathrm{TC}$ was significantly higher within the first 5 years of $\mathrm{BC}$ diagnosis, and then decreased over time, in $81 \mathrm{BC}$ then TC patients. The trend of SIR was same with our results, the difference in the cut-off year may be the result of different sample size. This result prompted consideration about the screening and treatment of individuals with the co-occurrence of these two diseases.

Screening is an approach to detect a disease early in asymptomatic individuals, but it may lead to a more aggressive operation. As a result, it is important for clinicians to recognize high-risk individuals with a $\mathrm{BC}$ history. Our study indicated to some degree that black women with BC should be focused on, even 3 years after $\mathrm{BC}$ diagnosis. Besides, a primary tumor located in an upper-outer, central, or overlapping site should also be carefully assessed, high tumor grade and histology with both ER and PR positive expression are other important features. BC patients with these features have exceeded risk to develop TC. As a clinician, when making medical decision for $\mathrm{BC}$ patients with these predictive factors, we should avoid to choose therapeutic methods those may increase the incidence of $\mathrm{TC}$, which was the meaning for us to recognize these factors. In the previous study, Marcheselli et al. [2] demonstrated that human epidermal growth factor receptor 2 (HER-2) positivity, and BRCA1 or BRCA2 mutation had an effect on the risk of second primary neoplasms, but the effect was not limited to TC. These SIR influent factors in our manuscript are new with regard to the relationship between $\mathrm{BC}$ and TC. Regarding to the intensity of screening, as the highest excess risk was 1.61/10,000 in black women, a routine screening intensity is sufficient, however, clinicians should still consider the possibility of further developing $\mathrm{TC}$ in $\mathrm{BC}$ patients, especially individuals with black race, upper-outer or central site tumor, high tumor grades, and both ER PR positive expression.

The present study demonstrated the clinicopathological features and survival of $842 \mathrm{BC}$ patients followed by $\mathrm{TC}$, represented a higher risk of TC development in $\mathrm{BC}$ 
patients than in the general population, especially within 3 years, and the predictive factors of $\mathrm{BC}$ patients developing TC. The present study had some limitations. First, although population-based cancer registries provided a lot of information to the SEER database, data on HER-2 status were recorded only since 2010; therefore, among the 842 patients, only 68 had HER-2 records, which prevented the identification of the molecular subgroup of $\mathrm{BC}$ and may cause bias on the analyzing of HER-2. Second, this study was based on data from a database rather than data from research in a clinic, which might reduce the level of evidence. Further studies in the clinic and laboratory should be conducted to reveal more insights on the relationship of $\mathrm{BC}$ and $\mathrm{TC}$.

\section{Conclusions}

$\mathrm{BC}$ patients who subsequently developed $\mathrm{TC}$ were more likely to be white and at a middle age, diagnosed with more T1 tumor, less lymph nodes metastasis, more infiltrating duct pathology, more 2 or 3 grade, and more hormone receptors positive disease. Compared with the features of $\mathrm{BC}$ only patients, they were younger, had a smaller tumor size, and had a relatively better prognosis. Additionally, age at the diagnosis of $\mathrm{BC}$ and the number of positive lymph nodes were prognostic factors to the OS of $\mathrm{BC}$ patients followed by TC after adjustment. Moreover, BC patients had a high risk of developing TC (SIR 1.22), especially within 3 years. Black women, primary tumor located in an upper-outer, central, or overlapping site, high grade tumor and with positive hormone receptors expression were risk factors of SIR, $\mathrm{BC}$ patients with these features showed an increased risk of TC development.

\section{Abbreviations}

BC: Breast cancer; Cl: Confidence interval; ER: Estrogen receptor; HER2: Human epidermal growth factor receptor 2; OR: Odds ratio; OS: Overall survival; PR: Progesterone receptor; SEER: Surveillance, Epidemiology, and End Results; SIR: Standardized incidence ratio; TC: Thyroid cancer

\section{Acknowledgements}

We would like to thank Editage for English language editing.

\section{Authors' contributions}

LST analyzed and interpreted the data, was the major contributor in writing and revise the manuscript. $Y J$ interpreted the data and was the writing assistance. SYW contributes to data analyzing. ZXA and ZLX were the major contributor to data collection. WBY and LP made the tables and figures in the manuscript. WYM helped to do publication decision. YM revised the first version of the manuscript. YJ designed the study concept. All authors have contributed to, read and approved the final manuscript for submission.

\section{Funding}

None.

\section{Availability of data and materials}

The datasets analyzed during the current study are available in the SEER*Stat software (version 8.3.6, download from https://seer.cancer.gov/data/options. html). A registration form needs to be completed before using and filter criteria need to be added. The datasets are also available from the corresponding author on reasonable request.
Ethics approval and consent to participate

Not applicable. Data is available in a public database, ethics approval is not applicable.

\section{Consent for publication}

Not applicable.

\section{Competing interests}

The authors declare that they have no competing interests.

\section{Author details}

'Department of Medical Oncology, the First Affiliated Hospital of Xi'an Jiaotong University, 277 West Yanta Road, Xi'an 710061, Shaanxi, China. 2Department of Medical Oncology, Shaanxi Provincial Tumor Hospital, Xi'an, China. ${ }^{3}$ Department of Translational Medicine, the First Affiliated Hospital of Xi'an Jiaotong University, Xi'an, China.

Received: 19 October 2018 Accepted: 13 November 2019

Published online: 29 November 2019

\section{References}

1. Ferlay J, Soerjomataram I, Dikshit R, Eser S, Mathers C, Rebelo M, et al. Cancer incidence and mortality worldwide: sources, methods and major patterns in GLOBOCAN 2012. Int J Cancer. 2015;136:E359-86. https://doi.org/ 10.1002/ijc.29210 Epub 2014 Oct 9.

2. Marcheselli R, Marcheselli L, Cortesi L, Bari A, Cirilli C, Pozzi S, et al. Risk of second primary malignancy in breast cancer survivors: a nested populationbased case-control study. J Breast Cancer. 2015;18:378-85. https://doi.org/ 10.4048/jbc.2015.18.4.378.

3. An JH, Hwangbo Y, Ahn HY, Keam B, Lee KE, Han W, et al. A possible association between thyroid cancer and breast cancer. Thyroid. 2015;25: 1330-8. https://doi.org/10.1089/thy.2014.0561 Epub 2015 Oct 27.

4. Grantzau T, Overgaard J. Risk of second non-breast cancer among patients treated with and without postoperative radiotherapy for primary breast cancer: a systematic review and meta-analysis of population-based studies including 522,739 patients. Radiother Oncol. 2016;121:402-13.

5. Raymond JS, Hogue CJ. Multiple primary tumours in women following breast cancer, 1973-2000. Br J Cancer. 2006;94:1745-50.

6. Evans HS, Lewis CM, Robinson D, Bell CM, Møller H, Hodgson SV. Incidence of multiple primary cancers in a cohort of women diagnosed with breast cancer in Southeast England. Br J Cancer. 2001;84(3):435-40.

7. Joseph KR, Edirimanne S, Eslick GD. The association between breast cancer and thyroid cancer: a meta-analysis. Breast Cancer Res Treat. 2015;152:17381. https://doi.org/10.1007/s10549-015-3456-6 Epub 2015 Jun 10.

8. Kuo JH, Chabot JA, Lee JA. Breast cancer in thyroid cancer survivors: An analysis of the surveillance, epidemiology, and end Results-9 database. Surgery. 2016;159:23-9. https://doi.org/10.1016/j.surg.2015.10.009 Epub 2015 Oct 29.

9. Garner CN, Ganetzky R, Brainard J, Hammel JP, Berber E, Siperstein AE, et al. Increased prevalence of breast cancer among patients with thyroid and parathyroid disease. Surgery. 2007;142:806-13.

10. Park CM, Lee YD, Oh EM, Kim KI, Park HK, Ko KP, et al. The prognosis and treatment of primary thyroid cancer occurred in breast cancer patients: comparison with ordinary thyroid cancer. Ann Surg Treat Res. 2014;86(4): 169-76. https://doi.org/10.4174/astr.2014.86.4.169.

11. Shi XZ, Jin X, Xu P, Shen HM. Relationship between breast cancer and levels of serum thyroid hormones and antibodies: a meta-analysis. Asian Pac J Cancer Prev. 2014;15(16):6643-7.

12. Beatson GT. On the treatment of inoperable cases of carcinoma of the mamma: suggestions for a new method of treatment with illustrative cases. Lancet. 1896;148:104-7.

13. Liu YR, Jiang YZ, Yu KD, Shao ZM. Different patterns in the prognostic value of age for breast cancer-specific mortality depending on hormone receptor status: a SEER population-based analysis. Ann Surg Oncol. 2015;22:1102-10. https://doi.org/10.1245/s10434-014-4108-5.

14. Sun LM, Lin CL, Liang JA, Huang WS, Kao CH. Radiotherapy did not increase thyroid cancer risk among women with breast cancer: a nationwide population-based cohort study. Int J Cancer. 2015;137:2896-903. https://doi. org/10.1002/ijc.29667 Epub 2015 Jul 14. 
15. Yu GP, Schantz SP, Neugut Al, Zhang ZF. Incidences and trends of second cancers in female breast cancer patients: a fixed inception cohort-based analysis (United States). Cancer Causes Control. 2006;17(4):411-20.

16. Wei X, Li Y, Zhang S, Ming G. Evaluation of thyroid cancer in Chinese females with breast cancer by vascular endothelial growth factor (VEGF), microvessel density, and contrast-enhanced ultrasound (CEUS). Tumour Biol. 2014;35:6521-9. https://doi.org/10.1007/s13277-014-1868-2.

17. Lal G, Groff M, Howe JR, Weigel RJ, Sugg SL, Lynch CF. Risk of subsequent primary thyroid cancer after another malignancy: latency trends in a population-based study. Ann Surg Oncol. 2012;19:1887-96. https://doi.org/ 10.1245/s10434-011-2193-2

18. Zhang Y, Liang J, Li H, Cong H, Lin Y. Risk of second primary breast cancer after radioactive iodine treatment in thyroid cancer: a systematic review and meta-analysis. Nucl Med Commun. 2016;37:110-5. https://doi.org/10.1097/ MNM.0000000000000419.

19. Lin CY, Lin CL, Huang WS, Kao CH. Risk of breast cancer in patients with thyroid cancer receiving or not receiving I-131 treatment: a nationwide population-based cohort study. J Nucl Med. 2015;57:685-90. https://doi.org/ 10.2967/jnumed.115.164830.

20. Ahn HY, Min HS, Yeo Y, Ma SH, Hwang Y, An JH, et al. Radioactive iodine therapy did not significantly increase the incidence and recurrence of subsequent breast cancer. J Clin Endocrinol Metab. 2015;100:3486-93. https://doi.org/10.1210/JC.2014-2896.

21. Lin W, Ren FM, Ren ZF. The contribution of radiotherapy to subsequent thyroid cancer risk may be confined to a subgroup of breast cancer patients. Int J Cancer. 2016;138(7):1802. https://doi.org/10.1002/ijc.29907.

\section{Publisher's Note}

Springer Nature remains neutral with regard to jurisdictional claims in published maps and institutional affiliations.

Ready to submit your research? Choose BMC and benefit from:

- fast, convenient online submission

- thorough peer review by experienced researchers in your field

- rapid publication on acceptance

- support for research data, including large and complex data types

- gold Open Access which fosters wider collaboration and increased citations

- maximum visibility for your research: over $100 \mathrm{M}$ website views per year

At $\mathrm{BMC}$, research is always in progress.

Learn more biomedcentral.com/submissions 